\title{
Sequential Infusion of Anti-CD22 and Anti-CD 19 Chimeric Antigen Receptor T Cells for a Pediatric Ph-Like B-ALL Patient That Relapsed After CART-Cell and Haplo-HSCT Therapy: A Case Report and Review of Literature [Corrigendum]
}

Hua J, Qian W, Wu X, et al. Onco Targets Ther. 2020;13:2311-2317.

The authors of this paper have advised that the author and affiliation list on page 2311 is incorrect. The correct author and affiliation list is as follows:

Jingsheng Hua ${ }^{1,2, *}$

Weiqing Qian ${ }^{3, *}$

Xiaoxia $\mathrm{Wu}^{\mathrm{l}, *}$

Lili Zhou'

Lei $\mathrm{Yu}^{4}$

Suning Chen'

Jian Zhang'

Huiying Qiu'

'Jiangsu Institute of Hematology, National Clinical Research Center for Hematologic Diseases, The First Affiliated Hospital of Soochow University, Institute of Blood and Marrow Transplantation, Collaborative Innovation Center of Hematology, Soochow University, Suzhou 215006, Jiangsu, People's Republic of China; ${ }^{2}$ Department of Hematology, Taizhou Municipal Hospital, Taizhou 318000, Zhejiang, People's Republic of China; ${ }^{3}$ Suzhou Vocational Health College, Suzhou, Jiangsu, People's Republic of China; ${ }^{4}$ College of Chemistry and Molecular Engineering, East China Normal University, Shanghai, People's Republic of China

*These authors contributed equally to this work
The authors have also advised that the correspondence section on page 2311 is incorrect. The correspondence section should read as follows:

\author{
Correspondence: Huiying Qiu; Jian Zhang \\ Tel +8613912792913 \\ Fax +8651267781850 \\ Email qiuhuiying8303@suda.edu.cn; crystalzj06@।63.com
}

\section{Publish your work in this journal}

OncoTargets and Therapy is an international, peer-reviewed, open access journal focusing on the pathological basis of all cancers, potential targets for therapy and treatment protocols employed to improve the management of cancer patients. The journal also focuses on the impact of management programs and new therapeutic agents and protocols on patient perspectives such as quality of life, adherence and satisfaction. The manuscript management system is completely online and includes a very quick and fair peer-review system, which is all easy to use. Visit http://www.dovepress.com/ testimonials.php to read real quotes from published authors. 